\title{
Disaster risk reduction through community participation
}

\author{
S. S. Zubir ${ }^{1,2}$ \& H. Amirrol ${ }^{2}$ \\ ${ }^{1}$ Department of Architecture, Faculty of Architecture, \\ Planning \& Surveying, Universiti Teknologi MARA, Malaysia \\ ${ }^{2}$ MERCY Malaysia, Malaysia
}

\begin{abstract}
Disaster risk reduction is a totalizing framework that was established from the conception of protecting communities from hazards and minimizing their vulnerability to the risks of disaster. One of the many aspects of disaster risk reduction is through the participatory involvement of the local community. The paper will discuss the application of systematic disaster management in managing emergency and post emergency situations by adopting the role of civil society in the context of community based approaches. These approaches are proven to be adaptive and comprehensive enough in progressing through the hard times during and after the event of disaster. The paper will outline comprehensive and integrated methods from previous experiences in assisting the process of internalizing the concept of disaster risk reduction and strategic planning for disaster management. It is hoped that from the shared experience discussed in this paper will contribute to a more resilient community that are well informed and prepared on the culture of disaster risk reduction and disaster management practices.
\end{abstract}

Keywords: community based disaster management (CBDRM), disaster risk reduction, community participation, MERCY Malaysia.

\section{Introduction}

The Millennium Development Goals (MDGs) adopted by the international community in 2000 as the global framework for development need to take into account issues of vulnerability, disaster management and risk assessment. Disasters can wipe out years of development outcomes. Large-scale disasters 
destroy livelihoods in a matter of minutes while smaller recurrent disasters wear down resources and resilience, exposing people to greater risks of extreme poverty, disease and poor health. At a macro-economic level, disasters impact on levels of economic development through extensive damage of infrastructure as well as loss of human resources. Such setbacks seriously limit the ability of nations to make the investments in social development needed to achieve the MDGs.

While natural disasters cannot be avoided, adopting adequate risk reduction approaches can considerably reduce the scale of damage and protect prior development gains. A sound governance structure for disaster reduction allows and encourages expressions of volunteerism and norms of social reciprocity during natural disasters. In reality, governance and institutional policy frameworks for incorporating volunteers and volunteer involving organizations (VIOs) into risk reduction management systems are largely absent [1]. At its most benign level, this results in wastage in terms of missing out on the impact of well prepared and coordinated volunteer responses. At its worst, overlooking the spontaneous but often untrained volunteer responses at the planning stage can result in life-threatening situations for disaster victims as well as for volunteers themselves. Public awareness and recognition of the role and contribution of volunteers and VIOs is a critical ingredient to a comprehensive risk reduction management plan. In the immediate aftermath of a disaster, the first response, both spontaneous and organized, generally comes from local communities. To take full advantage of community resilience after a disaster, affected communities need to be well prepared. A first step in this direction is the formal recognition of the value of local volunteer efforts. Such recognition needs to be translated into provision of adequate financial and human resources and the integration of effective volunteer management practices into disaster management programs.

\section{Legal and institutional frameworks}

There are multiple stakeholders to be considered in any disaster risk management plan. In addition to recognizing that volunteers and VIOs have roles to play in planning activities, governments also need to ensure that appropriate legal and regulatory frameworks are in place to allow full expression of the potential contribution of volunteerism to disaster risk management. Regulatory frameworks also encourage volunteerism by empowering volunteers with formal roles during and in the aftermath of disasters. In the Indian example, the damage assessment reports of volunteer teams were formally recognized as official reports. This empowered and encouraged the volunteers working in the area of damage assessment. Volunteer contributions to disaster reduction are most effective when mechanisms of decentralized governance are mutually reinforcing. Disaster risk management planning which takes into account the roles of VIOs at the national, regional, municipality and local levels may be critical in reducing the impact of natural hazards. 
Decentralization is an important factor in developing comprehensive plans for disaster risk management. Local authorities need to be empowered to deal effectively with risk reduction activities and with pooling of the human resources required to carry out both preparedness and response activities. Decentralizing the leadership and authority of disaster risk management to the regional, municipality or local level facilitates more effective volunteer management in preparedness and response. It encourages local participation and engages people to volunteer based on their own self-interest and community well being. Decentralization coupled with multi-stakeholder participation in the planning process also creates a more inclusive atmosphere and leads to greater community participation. Working in partnership with communities at risk builds up local capacity and coping mechanisms to respond. Increasing awareness of risks within communities inspires more people to get involved to prevent the loss of their own livelihoods. Four central dimensions lie at the core of such a developmental framework. These are:

a) The need to stimulate the emergence of qualitatively decent total living/working/learning environments.

b) Identifying the need to use reconstruction and rebuilding initiatives to generate employment.

c) The need to stimulate social cohesion through a reflexive design and planning program.

d) Roles of community as an important process

\section{Multi-stakeholder participation}

Risk reduction management is beyond the capacity of governments alone. Multi stakeholder participation is most effective. The 2004 UNDP global report on reducing disaster risks states that the goal should be a strong civil society and a strong State working in partnership with a socially committed private sector. Participation of local communities and VIOs is crucial both to understanding local needs and empowering people to address those needs as well as to send a message to local communities that their voice is valued. This strengthens the motivation to get involved. An important lesson of emergency response work in recent times has been the knowledge that takes into account the vulnerabilities and capacities of local communities as the essential ingredient for effective risk reduction planning. The Yokohama Review notes that more candid dialogue among stakeholders at local level is required to identify longer-term objectives. With this in mind, Governments should seek new and creative ways of engaging communities in the dialogue and decision making process and, at the same time, build awareness by involving volunteers and VIOs in disaster planning and preparedness activities. At local level, Governments should seek ways to encourage volunteerism in the knowledge that it fosters stronger community participation and more inclusive governance.

However, building local capacity requires investment in both human and financial resources. Volunteerism is cost effective but not cost free even if the costs are far outweighed by the benefits. Investments in VIOs have traditionally 
been limited to the disaster response phase. To ensure sustainability, investment is also needed in capacity building of VIOs for risk reduction activities. There is significant evidence of strong linkages between the quality of emergency responses and the existence of sound volunteer management systems. Governments should invest in ensuring that appropriate structures are in place for volunteer management both during emergencies and in non-emergency periods. Investment is also needed to provide training for volunteers in public awareness, disaster preparedness and emergency response and to ensure they have appropriate tools to perform their duties. Beyond these standard approaches to recovery, new studies have illuminated the potential role of social networks and civil society in explaining the speed of post-crisis recovery. Social ties can serve as "informal insurance" mechanisms allowing victims to draw upon readymade support networks for financial, physical, and logistic guidance [2]. Furthermore, more politically active and integrated communities can better present their demands to and extract resources from authorities.

\section{Mainstreaming adaptation through disaster risk reduction}

Disaster reduction is most effective at the community level where specific local needs can be met. When used alone, government and institutional interventions often prove to be insufficient and frequently are seen to be sporadic and only responding to crises. A top-down approach is inclined to ignore local perceptions, needs and the potential value of local resources and capacities in the process. A community based disaster reduction effort is most successful when they involve the direct participation of the people most likely to be exposed to hazards - in the planning, decision-making, and operational activities at all levels of responsibility. Local leaders, drawn from political, social and economic sectors of society need to assume a primary responsibility for the protection of their own community. Surprisingly, emergency relief assistance far exceeds resources invested to develop local disaster risk reduction capabilities. Communities must be aware of the importance of disaster reduction for their own well-being. It then becomes necessary to identify and impart essential skills that can translate risk awareness into concrete practices of sustained risk management. Such an approach needs to develop activities that can strengthen communities' capacities to identify and cope with hazards, and more broadly to improve residents' livelihoods. As more research on development has been conducted in various fields in recent years, the approach to disaster mitigation is becoming more and more community-based [3-7] and much more effort has been put into incorporating disaster management aspects into the holistic development of communities. Maskrey [8] has rightly pointed out that, disaster management should not be treated as one single issue but should be incorporated into the socioeconomic activities of local people. The rationale for community involvement or community-based activities is now well rehearsed [9]. Because community-based activities (and community-based organizations) are deeply rooted in the society and culture of an area, they enable people to express their 
real needs and priorities, allowing problems to be defined correctly and responsive measures to be designed and implemented.

Community involvement is often faced with the problem of sustainability [10]. Government, non-government and international organizations implement various programs before and after the disasters. Most of them are very successful during the project period, and gradually diminish as the years passed. There are many reasons for gradual decrease of people's involvement in a project. The most common elements are partnership, participation, empowerment and ownership of the local communities. Unless the disaster management efforts are sustainable at individual and community level, it is difficult to reduce the losses and tragedy. While people should own the problems, consequences and challenges of any mitigation and/or preparedness initiative, it is necessary to see people's involvement in a broader perspective, which is related to policy and strategy. Another way in which dense civil society and high levels of social capital assist recovery is through information diffusion and the overcoming of barriers through collective action [11]. Neighbours with greater levels of social trust and "bridging" social capital share information about bureaucratic procedures and upcoming deadlines, monitor public space to prevent dumping, and deter looting in their community. In Kobe, for example, even as city officials sought to clarify rebuilding plans, local residents organized to plan the layout of their block. In their comparative study of post-disaster rebuilding in tsunamiaffected India and Japan, Nakagawa and Shaw [12] demonstrated that individuals living in areas with higher levels of social capital were more satisfied with the process of town planning. The preliminary analysis indicates that civil society plays a key role in drawing local residents back into a disaster-ravaged city. Those areas with better-connected, more active citizens brought back more residents to their neighbourhoods and sped up the time required for the reconstruction.

\section{Community leadership and relationships}

Any system of local planning and protection must be integrated into larger administrative and resource capabilities such as provincial, state and national disaster plans and risk reduction strategies. It is equally important to realize that communities cannot implement community-based disaster mitigation alone.

Viable forms of community-based disaster reduction depend on a favourable political environment that understands, promotes and supports this participation process. A special effort is required to recall locally valued traditional coping mechanisms and strategies, while modern concepts and technology can provide additional innovative approaches. While modern-day disaster relief involves greater sophistication than past attempts following tragedies, certain tropes remain the same. Scholars regularly divide post-disaster time into three periods: the emergency period, the restoration period, and the reconstruction period. During the emergency period, the focus is on rescue and recovery, with rescuers seeking to save the lives of those still trapped beneath buildings, or provide temporary shelters and food for survivors whose homes were damaged. Once the 
initial relief phase has been completed, the government and non-governmental organizations seek to remove damaged infrastructure, such as collapsed roads, bridges, and the like, and begin replacing these public facilities. This is the restoration period, when gas, water, sewage, and electricity utilities are reconnected, and when temporary housing may be built nearby. The final period of reconstruction seeks to house the survivors either in their old homes, which have been repaired, or in new shelters as close to their old neighbourhood as possible.

Policy-planners should think carefully about the ways that they can facilitate the construction and maintenance of social networks. For example, providing communities and community groups with communications devices such as cell phones and e-mail connections can help them stay in contact during the post disaster diaspora. Furthermore, NGOs and the government can focus on setting up not just temporary homes for people to live in, but meeting places for local community groups. Officials can also sponsor information sessions specifically for established faith-based or neighbourhood-based groups and to house relocated communities together, as opposed to separate locations. These are simple and relatively low-cost solutions, but they may have far-reaching positive consequences for communities struck by disaster. It has been a common notion that grass root initiatives are the responsibilities of the non-government organizations. NGOs have been the leading actors in this field for several years, and contributed to the development of the field $[13,14]$. However, many of the NGO activities face the problem of sustainability over a longer period of time, especially once the NGO withdrew from the field. Continuation of community activities over a longer period of time needs a policy environment at local level, as well as local institutions to continue the activities. Thus, even though the initiatives are started with the NGO interventions, it is important to link them to the local government activities, and incorporate them into policies. Thus, the major challenges of the community based disaster risk management (CBDRM) are: sustainability of the efforts in the community level, and incorporation of the CBDRM issues in the policy level. To be effective and to create sustainable impact, the application of the CBDRM must go beyond the initiative of communities, NGOs and a handful of local governments. As part of an advocacy for more responsive and effective governance, national and state level governments should look at integrating CBDRM in their policy and implementing procedures.

\section{MERCY Malaysia, technical team and CBDRM}

As a recent established relief organization, MERCY Malaysia's main objective was to assist in medical services but as these areas required major reconstruction interventions, therefore, services from the allied built environment professions have been included in the rebuilding program. As a medical relief organization, MERCY Malaysia had to widen its areas of expertise within a short period of time. Most of the time, we know little about what to expect, but with the support of volunteers from a multi-faceted background, MERCY Malaysia finally 
managed to gather most of the required professionals to start its rebuilding and reconstruction projects. With the inception of its Technical Team in 2005, MERCY Malaysia is committed to analyze, research and propose effective means of disaster management by approaching each of our reconstruction projects carefully. This commitment include proposing projects and programs which promotes community participation and enabling them to protect themselves against disaster using the totalizing frameworks of CBDRM.

The technical team was established in an ad-hoc manner when quick responses and needs for rehabilitation and reconstruction works in Aceh arise, due to the 2004 Indian Ocean Tsunami. Through networks of friends practicing in the built environment industry, a group of professional architects, civil and structural engineers, mechanical engineers, land surveyors, quantity surveyors, building contractors and designers volunteered to help. From there, the technical team progressed systematically, and have completed projects in Indonesia, Bangladesh, Myanmar, Sudan, Pakistan, Iran, Sri Lanka, and Malaysia. The strong spirit of humanity keeps the team progressively active and is always ready to participate in any disaster response missions. The technical team also has developed systematic ways in dealing with specific technical issues, ranging from planning and design, structural, mechanical, contract administration, and to the bigger scope of disaster risk reduction and CBDRM. These approaches helped in maintaining the structure of the team to always be prepared in any kind of situations and responses needed. We believe that technology must be manageable by locals for their benefit. The use of technology and techniques should always be constructive to civilization. MERCY Malaysia has collaborated with local and foreign experts from Universiti Teknologi MARA, Universiti Sains Malaysia, Kyoto University, Japan, Universitas Syiah Kuala, Banda Aceh, National Society for Earthquake Technology, Nepal, United Nations' agencies, and many other relief and humanitarian agencies to ensure that knowledge, expertise and experiences will be shared in a systematic networks of professionals, and can be delivered efficiently to the community and beneficiaries.

Disaster risk reduction involves activities aimed at protecting communities from hazards and minimizing their vulnerability to disaster risks. It moves beyond the traditional disaster management approach of simply focusing on response, rehabilitation and rebuilding after a disaster. Disaster risk reduction has a two-fold mission: i) to build societies that are resilient to natural hazards, and ii) to ensure development does not increase vulnerability to hazards. MERCY Malaysia has introduced several programs centred on disaster risk reduction amongst vulnerable groups of the community, where MERCY Malaysia implemented CBDRM programs to support the government's effort to improve disaster preparedness. Disaster risk reduction has emerged as an essential factor in sustainable development. In the context of disaster risk reduction, development is sustainable if it recognizes potentials hazards and incorporates measures to reduce a community's vulnerability to these hazards. At a minimum, development activities must not increase a community's vulnerability. The Hyogo Framework for Action 2005-2015: Building the Resilience of Nations and Communities to Disasters was adopted by 168 
countries, including Malaysia, at the United Nations World Conference on Disaster Reduction in Kobe, Japan, in 2005. It is a global blueprint that offers guiding principles, priorities for action and practical means for achieving disaster resilience for vulnerable communities. In implementing disaster risk reduction policies and other community-driven activities, MERCY Malaysia subscribes to the framework. Here are recent examples and lesson learnt from some of the CBDRM-based projects implemented by MERCY Malaysia [15].

\subsection{Tsunami Resource Centre, Indonesia}

The Tsunami Resource Centre (TRC) was established at the Universitas Syiah Kuala (UNSYIAH) in Aceh, Indonesia by MERCY Malaysia with funding support by the Force of Nature and opened in July 2007. MERCY Malaysia has conducted four main activities in TRC, which include i) drafting a resource book for disaster education, ii) TRC visit day for elementary school children, iii) School Watching Workshop for Elementary Schools' Headmasters, and iv) Disaster Education Workshop for the Education Faculty students of UNSYIAH. The resource book for disaster education was used at Disaster Education Workshop for Education Faculty students to introduce how to teach disaster-related issues and it would become their guidebook when they pursue the teaching job in the future. The four workshops have taken place in 2008, with a total number of 500 student participants. For the event of TRC Visit Day, the resource centre was visited by 1300 elementary students from 32 schools in Banda Aceh and Aceh Besar, from July to December 2008. Through the visit, the children learned about disaster and disaster preparedness in a 3-hours session, through video screening, games and simulation activities. School Watching Workshop for Elementary Schools' Headmasters was also conducted in 2008, aimed to deliver basic knowledge on disaster and disaster preparedness through risk and hazard mapping practices, and to obtain their understanding of the importance of disaster education in schools. The headmasters were also encouraged to set up their own disaster management committee at the school level.

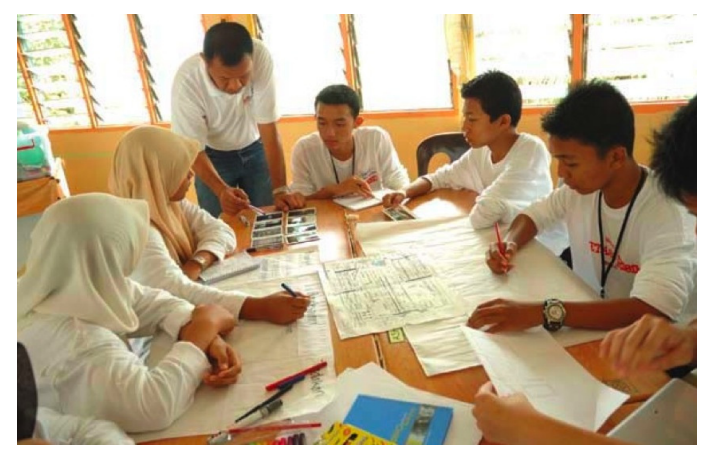

Figure 1: Facilitating disaster management planning in schools, preparing students to take responsibility for their safety in the event of emergency and disaster. 


\subsection{Island disaster management, Maldives}

Maldives is a country that is regularly exposed to natural hazards. The 2004 Indian Ocean tsunami struck Maldives, resulting in over 80 deaths. In addition, $30 \%$ of the population of 300,000 were displaced, $25 \%$ of the 200 inhabited islands were severely damaged and $10 \%$ were totally destroyed; 14 islands had to be evacuated with total losses estimated to be at USD 472 million, equating to $62 \%$ of their GDP. With funds from the Malaysian Ministry of Finance, MERCY Malaysia implemented a CBDRM project in support of the Maldives government's effort to improve disaster preparedness in the island-nation. The project aims to engage target communities to develop Island Disaster Management Plans for the island. During the two-year project, Island Disaster Management Plans were developed with the community on four islands in Haa Alifu and Haa Dhaalu Atolls, the two northern-most Atolls of Maldives. The project benefited some 15,500 people on these four islands. In developing the plan, each community were asked to identify the hazards and vulnerabilities confronting their community and develop solutions to reduce the disaster risk, and therefore make the island safer and the community to be more prepared. In addition, a Disaster Management Committee and taskforces for each island were formed to conduct response activities in the event of disaster on their island. MERCY Malaysia, along with its implementing partner in Maldives, Care Society, also worked with local communities developing a three-month community based disaster risk reduction project.

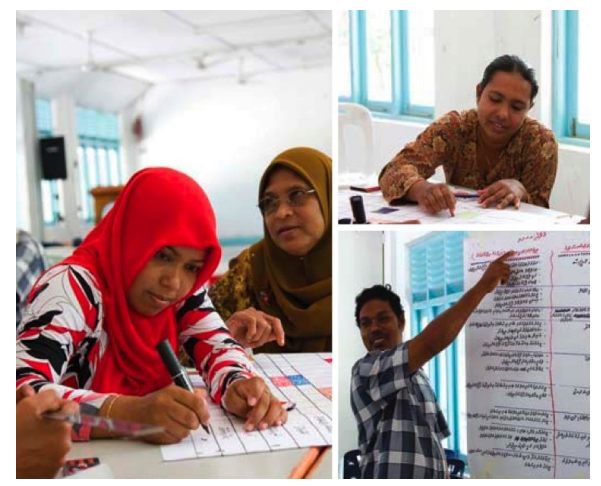

Figure 2: Local communities participated in the development of the Island disaster management plan, an effort to improve disaster preparedness amongst community.

\subsubsection{Disaster response and reconstruction works, Myanmar}

Another example of the adaptation and implementation of CBDRM is during relief and respond efforts undertook in Myanmar, which was hit by Cyclone Nargis in 2008. MERCY Malaysia worked on the reconstruction of health facilities in Dedaye Township - an area severely hit by the cyclone. Many of the health facilities consisting of rural health centres (RHC), sub rural health centres 
(SHRC), station hospitals and a township hospital were damaged. MERCY Malaysia was involved in the rebuilding of two RHCs, eight SRHCs, two station hospitals and a township hospital in the division. The first project was to rebuild the Chaung Hpyar SRCH, a facility completely destroyed by the cyclone. Reconstruction works on four other facilities - Toe (RHC), Hie Seik Chaung Gyi (SRHC), Ah Kei Chaung Wa (SRHC) and Pyan Doe (SRHC) began in December 2008, while rebuilding efforts on Taung Tan (SRHC), Taw Kyaik (SRHC), Ywa Tan Shey (SRHC) and Ma Yaung Nouk (SRHC) began in January 2009. Currently, all health facilities have been completed and are functioning well. The design of these hospitals and health centres are made cyclone-proof with extra safety measures included in the design and construction of all buildings. To compliment the new buildings, hospital and community preparedness training programs for communities were also included as part of the CBDRM effort. Cyclone Nargis did not only cause massive devastation to the people of Myanmar - it was a wakeup call for disaster responders and humanitarian workers around the world. As the world sat rigid in shock, continuous lobbying for international humanitarian response from all sectors aggressively took place. And it became apparent that the complexities of developing trust and partnerships in fulfilling the functions of humanitarian aid are key to saving lives in times of disasters. Cyclone Nargis taught us many things and one key lesson is that, disaster response alone is not enough. It taught us to respect cultures and strive to advocate for political will. It taught us that regional and international partnerships necessitate the quality of service delivery.

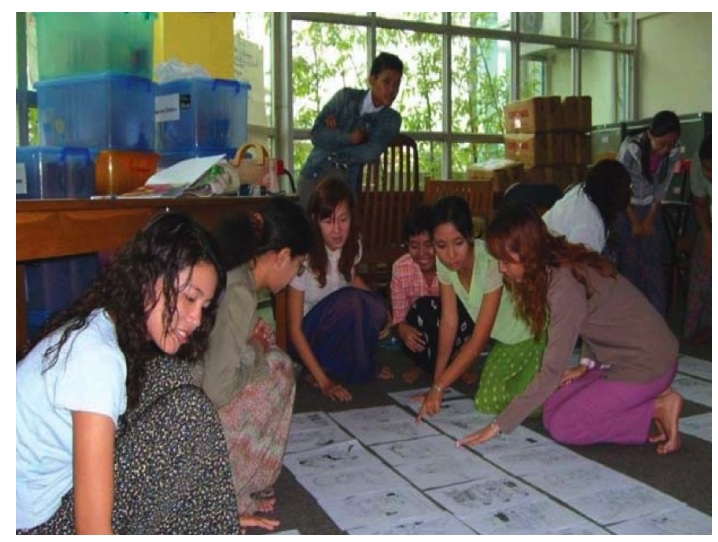

Figure 3: CBDRM process with local communities in Dedaye Township, planning and strategizing relief activities, reconstruction works and a long term disaster preparedness programs.

\section{Conclusion}

In many disaster response initiatives, community-based disaster response works well because it responds quickly to urgent needs that achieve relief at the early 
stages. The approach is also capable to mobilizes solidarity among the members of a community and therefore creates social capital, allowing women and the minorities to be a part of the reconstruction process, strengthens local institutions, and it can achieve good planning while does not exclude high quality results. On top of that, community-based housing reconstruction may limit disaster vulnerability and it can be done with good monitoring in achieving required accountability. In this context, people must understand and accept that they also have a responsibility towards their own survival - it is not simply a matter for governments, organizations and VIOs to find and provide solutions.

Existing grass roots and community-based organizations at community level, including women organizations, should be reinforced, for them to take action and participate in disaster risk reduction activities. Transfer of expertise at a local level, e.g. early warning systems and procedures suited to small-scale requirements, as well as transfers of local experiences, and their thematic application within various communities have to be developed. Wholesome recovery of housing and livelihoods must be encouraged and communities must be allowed to set their own priorities within the rebuilding process. Often expectations on time, quality and involvement are set unrealistically. Communities must be able to set their own priorities and define their own timing. This may imply that at first safe rooms or core houses are built or that damaged houses, which can be shared are repaired.

Good management is very crucial in the CBDRM frameworks. Shortcomings in the management which can obstruct the implementation process include: slow management; insufficient information for the public; issuance of technical standards which lack in clarity and simple usefulness; lack of adequate construction materials; areas of operation are geographically scattered. Community based reconstruction also requires work on governance issues at village level. It should be encouraged to report fraud to the authorities. Furthermore, agencies should commit themselves to accept and process complaints. Good governance will only work through transparent processes. Open information to communities is also crucial, as broad scale support to the involved communities is required continuously and should include the dissemination of standards and the information concerning rights and access to support. Coordination is best done locally and in a decentralized way to appropriate lower institutional levels. In addition, the Government's role as a regulator needs to be strong. The prime role of government is to regulate and to integrate for longer-term recovery, as lots of immediate reconstruction turns out to be piecemeal. In this respect clear technical standards and the guaranteeing of their broad acceptance is a crucial point. In addition to that the reliable support on logistics and material availability is a key factor. Governmental and nongovernmental organizations need to set up sustainable network organizations, which are capable to institutionalize disaster relief action on a local level. These networks can also increase multi-stakeholder preparedness for natural disasters and establish resource centres that organize the outreach to local communities. 


\section{References}

[1] United Nations Development Program, Disaster Risk Reduction, Governance and Volunteerism, in: World Conference in Disaster Reduction, Kobe: UN Volunteers, 2005.

[2] Nakagawa, Y. and Shaw, R., Social Capital: A Missing Link to Disaster Recovery, in: International Journal of Mass Emergencies and Disasters, Vol. 22 (1), pp. 5-34, 2004.

[3] Beggs, J., Haines and V., Hurlbert, J., Situational Contingencies Surrounding the Receipt of Informal Support, in: Social Forces, 75 (1), pp. 201-222, 1996.

[4] Blaikie, P., Cannon, T., Davis, I. and Wisner, B., At Risk: Natural Hazards, People's Vulnerability, and Disaster, Routledge, London, 1994.

[5] Twigg, J., The Age of Accountability? Future Community Involvement, in: Disaster Reduction. Australian Journal of Emergency Management, 14(4): 51-58, 1999.

[6] Quarantelli E. L., Conceptualizing Disasters from a Sociological Perspective, in: International Journal of Mass Emergencies and Disasters, 7: 243-251, 1989.

[7] Mileti D. S., Disasters by Design. Washington D.C: Joseph Henry Press, 2001.

[8] Shaw, R. and Okazaki, K., Sustainability in Grass-roots Initiatives: Focus on Community-based Disaster Management. Kobe, UNCRD, 2003.

[9] Maskrey, A., Disaster Mitigation: A Community-based Approach. Oxfam, Oxford, 1989.

[10] Shaw R., Community based Disaster Management: Challenges of Sustainability, in: Proceedings, Third Disaster Management Practitioners' Workshop for Southeast Asia, Bangkok, Thailand, pp 113-117, 2004.

[11] Olson, M., The Logic of Collective Action; Public Goods and the Theory of Groups, Cambridge: Harvard University Press, 1965.

[12] Nakagawa, Y. and Shaw, R., Social Capital: A Missing Link to Disaster Recovery, in: International Journal of Mass Emergencies and Disasters, Vol. 22 (1), pp. 17, 2004.

[13] Jegillos, S. R., Issues and Policy, in: Shaw R. and Okazaki K. (eds) Sustainability in Grass-roots Initiatives: Focus on Community-based Disaster Management. UNCRD, pp 11-17, 2003.

[14] Murshed, Z., Community-based Disaster Risk Management in Southeast Asia: Concept and Framework, in: Proceedings, Third Disaster Management Practitioners' Workshop for Southeast Asia, Bangkok, Thailand, pp 1-7, 2004.

[15] MERCY Malaysia, MERCY Malaysia Annual Report 2008 - 2009. Kuala Lumpur, MERCY Malaysia, 2009. 